\title{
Energy expenditure related to the act of eating in Granadina goats given diets of different physical form
}

\author{
BY M. LACHICA, J.F. AGUILERA* AND THE LATE C. PRIETO \\ Estación Experimental del Zaidín (CSIC), Profesor Albareda, 1. 18008 Granada, Spain
}

(Received 14 September 1994 - Revised 12 February 1996 - Accepted 15 July 1996)

\begin{abstract}
The energy cost of eating was measured in four goats averaging $38 \mathrm{~kg}$ and fitted with rumen cannulas. Heat production (HP) was estimated in each goat over restricted periods of approximately 15 min while standing and eating continuously in a confinement respiration chamber. The animals were given feeds of different nature and physical form ranging from shrubs to concentrates. The energy cost of eating was calculated from the increment in HP above the average HP during the prefeeding period. The energy cost was related to the type and amount of feed consumed and also to the time spent eating. In a parallel experiment, similar amounts of the feeds eaten normally (oral feeding) were introduced into the rumen through a fistula. The increases in HP during and after fistula-feeding were negligible, which indicates that all of the increase in HP during eating is to be attributed to the energy cost of eating per se, mainly to the act of food prebension, mastication and propulsion in the alimentary tract. The rate of ingestion ( $\mathrm{g} \mathrm{DM} / \mathrm{min}$ ) ranged from 6.3 for fresh cut lucerne (Medicago sativa) to $46-99$ for concentrates. The energy cost of eating (J/kg body weight (BW) per $\mathrm{g}$ DM) averaged 7.08 for fresh cut lucerne, 9.02 for roughages and 1.55 for concentrates and was 2.24 and 4.75 for pelleted and chopped lucerne hay respectively. When the energy cost was expressed as a function of time spent eating, it ranged from 45 to $144 \mathrm{~J} / \mathrm{kg} \mathrm{BW}$ per min, depending on the physical form of the feed.
\end{abstract}

Goats: Rate of ingestion: Energy cost of eating

The usual technique for measuring the total energy expenditure by grazing animals is the factorial method, whereby the increase in energy expenditure above that measured in confinement is quantitatively estimated from calorimetric determination of the energy cost of various activities. The energy cost of each activity is then multiplied by the total time spent by free-ranging animals in that activity and total daily extra energy expended is calculated by summation. Most of the energy required by the grazing animal is due to increased muscular effort, mainly standing, walking and eating. The muscular activities of food prehension, mastication and propulsion in the alimentary tract are vital components of this complex. The contributions of other activities are usually considered negligible.

Heat production (HP) has been shown to increase during feeding in sheep (Ustjanzew, 1911; Graham, 1964; Young, 1966; Osuji et al. 1975), cattle (Adam et al. 1984), and ponies (Vermorel \& Mormede, 1991). This increase is not due to excitement since it is not abolished by $\beta$-adrenergic blockade and declines sharply, although not to the preprandial level, as soon as the animal stops eating (Webster \& Hays, 1968). Moreover, it is not significantly reduced if the food is removed through an oesophageal fistula as it is swallowed (Young, 1966). On the other hand no comparable increase in HP is found by putting food directly into the rumen (Osuji et al. 1975). The elevation in HP has, thus, been attributed to the energy cost of eating per se rather than to any consequence of the arrival of 
food in the gut. This cost is considered as proportional not to the amount of food eaten, but to the length of time spent feeding and to the nature and physical form of the feed consumed.

The energy cost of eating in ruminants has been well documented for sheep and cattle (for review see Blaxter, 1989) but, to our knowledge, there are no available data for goats. The present work aims to provide additional information published on this subject by specifically defining the energy cost of eating in Granadina goats. A brief account of some preliminary results has been given elsewhere (Lachica et al. 1994).

\section{MATERIALS AND METHODS}

\section{Animals}

Four adult female goats of the Granadina breed, of initial body weights $34.5,38 \cdot 0,38.6$ and $41.1 \mathrm{~kg}$ respectively, and fitted with rumen cannulas, were used in two parallel experiments. The animals were previously adapted for 3 weeks to the experimental conditions. They were allocated to individual metabolic cages in a temperature-controlled room $\left(24^{\circ}\right.$ ) and were given in a single meal (at 18.00 hours) a diet based on lucerne (Medicago sativa) hay alone or supplemented with different feeds. During the calorimetry runs, the animals were given the lucerne hay alone the previous day at 18.00 hours and each of the supplementary feeds immediately after the pre-feeding HP measurements. In all cases, the total daily metabolizable energy (ME) intake remained approximately isoenergetic at maintenance for all treatments. The energy requirements for maintenance were taken as $401 \mathrm{~kJ} / \mathrm{kg}$ body weight $(\mathrm{BW})^{0.75}$ per d (Aguilera et al. 1990). The compositions of these ingredients appear in Table 1. Water was always available.

\section{Respiration chamber}

Throughout the experiments, $\mathrm{O}_{2}$ consumption and $\mathrm{CO}_{2}$ and $\mathrm{CH}_{4}$ production of each goat were measured in a confinement respiration chamber and HP was calculated according to the equation of Brouwer (1965). All animals had been previously accustomed to confinement and to the routine procedures of the chamber operations. Chamber measurements were made over restricted periods of approximately $15 \mathrm{~min}$ to avoid the increase in HP associated with digestion and fermentation. The confinement-type respiration chamber was chosen because it is best suited and sufficiently accurate to fast response applications for measurement of gaseous exchange of animals. It depends on accurate measurement of gas concentration $\left(\mathrm{CH}_{4}, \mathrm{CO}_{2}\right.$ and $\left.\mathrm{O}_{2}\right)$. The chamber was air-tight, was made of transparent acrylic plates and was provided with an internal ventilation system. When an animal was introduced into the chamber an aliquot sample of the air of the chamber was taken for continuous analysis of its composition (by physical principles) and then returned to the chamber. Before the $\mathrm{CO}_{2}$ level increased to about $1 \%$, the chamber was manually flushed out for a few minutes with a stream of fresh air. Shortly after the start and before the end of each confinement period the chamber air was sampled and its composition measured. The volume of the system multiplied by the concentrations of $\mathrm{CH}_{4}, \mathrm{CO}_{2}$ and $\mathrm{O}_{2}$ gave the volumes of these gases present at each measurement and, by difference, the amounts consumed and produced. 


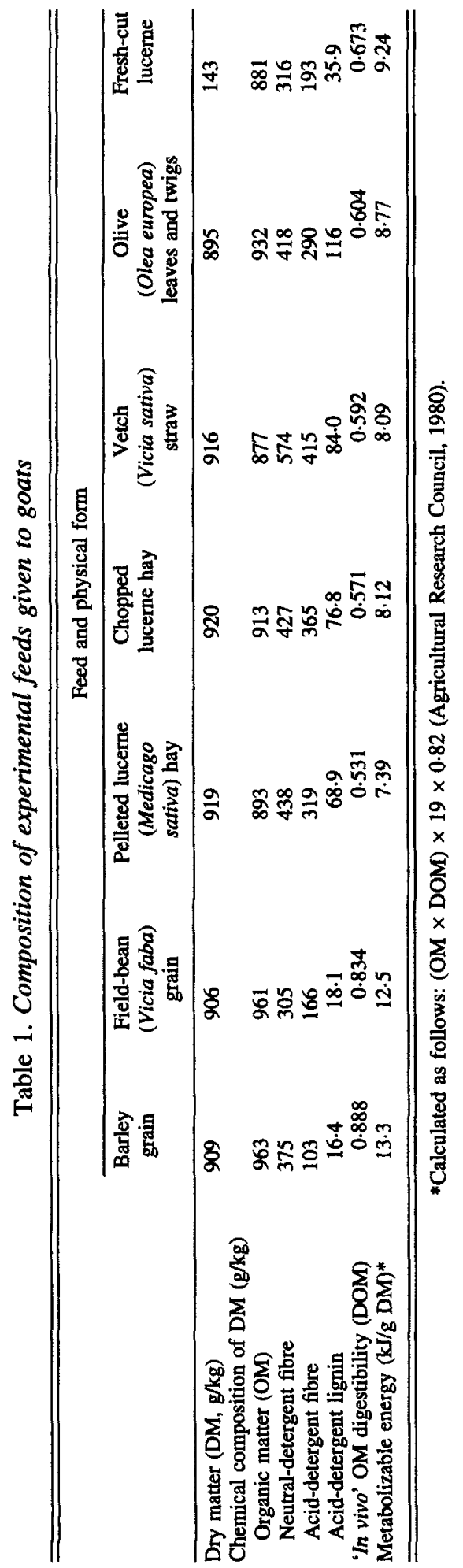




\section{Experimental design}

In Expt 1 a total of seven feeds were assayed. HP was estimated in each goat while allocated to the chamber over two consecutive restricted periods of approximately $15 \mathrm{~min}$, before and during eating each one of seven feeds of different nature and physical form. The feeds ranged from concentrates to shrubs and were consecutively given to the animals, after a period of adaptation of $7 \mathrm{~d}$ to the corresponding new diet, in the following order: barley grain, field-bean (Vicia faba) grain, pelleted lucerne hay, chopped lucerne hay, vetch (Vicia sativa) straw, olive (Olea europea) leaves and twigs, and fresh-cut lucerne. The feeds were not given in a randomized order for each animal separately and it has been assumed that the effects of any sources of variation that may have been confounded with feed as a result (for example, time) were small in comparison. The adaptation time was considered sufficient for goats to adjust to dietary changes and thus to eliminate any possible carry over effect from one feed to another, according to results obtained in previous experiments (Young, 1966; McLeod \& Smith, 1989; Vermorel \& Mormede, 1991). The goats were harnessed with slings to the sides of the cages in order to prevent them from lying down. They were given access to the feed by pulling a string to open the feed trough, located inside the chamber, containing the day's feed. The energy cost of eating was calculated from the increment in HP above the average HP of the prefeeding period. It was related to the type and amount of feed consumed and also to the time spent eating. In both cases it was expressed as $\mathrm{J} / \mathrm{kg}$ animal BW to facilitate comparison with published data from other species. For each dietary treatment (feed), two consecutive gaseous exchange measurements were carried out on each goat, from which a single value of heat increment was obtained. A set of four sequential gaseous measurements (one per goat) was performed per feed, and this constituted a calorimetry run. Each run was replicated twice, giving a total of $4 \times 2$ heat increment values per feed. In a parallel experiment (Expt 2), similar amounts of two of the feeds eaten normally by oral feeding (barley grain and pelleted lucerne hay) were introduced into the rumen of each goat through a fistula (fistula-feeding) while the goats were in the chamber. For this purpose it was opened during this process for a short period of time (usually less than $1 \mathrm{~min}$ ). Each goat underwent two sequential HP measurements for each of the two feeds offered, before $\left(\mathrm{HP}_{\mathrm{b}}\right)$ and after $\left(\mathrm{HP}_{\mathrm{a}}\right)$ being given the corresponding feed.

The data were subjected to ANOVA. They were treated as a 7 (feed; fixed effect factor) $\times 4$ (animal; random effect factor) factorial design in Expt 1 and, similarly, as a 2 (feed) $\times 4$ (animal) factorial design in Expt 2 . Some variates were transformed to a logarithmic scale before analysis to account for non-constant variance. In Expt 2 the comparisons between $\mathrm{HP}_{\mathrm{b}}$ and $\mathrm{HP}_{\mathrm{a}}$ were made within-run. The ANOVA was finally performed on the mean of the two runs for each feed-animal combination. Multiple range comparisons were performed by means of the Tukey test. Regressions were made when appropriate. In order to improve the estimation of the regression coefficients, an ANOVA in which variates were transformed to a logarithmic scale was used, in order to take animal and feed effects into account. Only the equations with the best fit were taken into consideration.

\section{RESULTS}

The mean increase in HP associated with eating ranged from 525 (barley grain) to 1168 (olive leaves and twigs) J/kg BW (Table 2), representing 29.3-52.3\% above the prefeeding level. The increased HP was highest for olive tree $(52.3 \%)$ and lowest for fresh-cut lucerne $(25.7 \%)$. Pelleted lucerne hay, chopped lucerne hay and vetch straw showed intermediate 


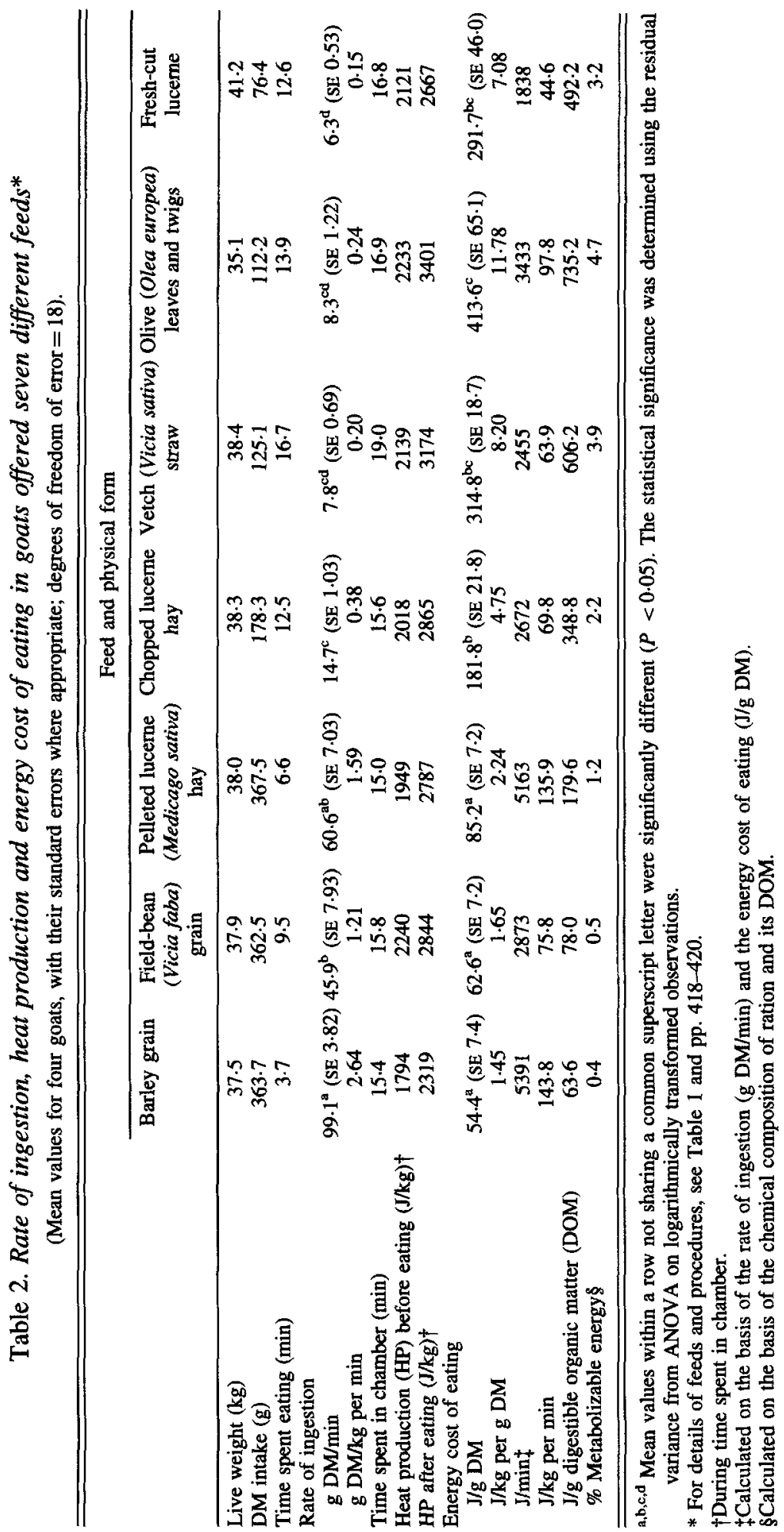


values $(43.0,42.0$ and $48.4 \%$ respectively). It was assumed that the size of the increment in HP above the prefeeding value was, for all the feeds assayed, adequate to allow an accurate estimation of the energy cost of eating.

The rate of ingestion was very variable and ranged from 6.3 to $99.1 \mathrm{~g} \mathrm{DM} / \mathrm{min}$, showing a marked relationship with the nature and physical form of the diet (Table 2). The rate was high for barley grain, pelleted lucerne hay and field-bean grain (99.1, 60.6 and $45.9 \mathrm{~g} \mathrm{DM} / \mathrm{min}$ respectively) and low for olive leaves and twigs, vetch straw and fresh-cut lucerne $(8.3,7.8$ and $6.3 \mathrm{~g} \mathrm{DM} / \mathrm{min})$, with chopped lucerne hay showing an intermediate value (14.7 $\mathrm{g} \mathrm{DM} / \mathrm{min})$. The rate of ingestion ( $R, \mathrm{~g} \mathrm{DM} / \mathrm{min})$ was positively related to the in vivo organic matter digestibility (DOM) and negatively related to the fibre content. The values of fresh-cut lucerne were not taken into account in these calculations, due to their high content of water. Significant correlations were found only with acid-detergent fibre (ADF, g/100 g DM) and with acid-detergent lignin (ADL, g/100 g DM). The equations with the best fit were:

$$
\begin{gathered}
\mathrm{R}=105.9-2.4 \mathrm{ADF} ; r-0.749 ; n \text { 24, } \\
(\mathrm{SE} \mathrm{13.5)}(\mathrm{SE} 0.45) \\
\ln \mathrm{R}=4.84-1.03 \mathrm{ADL} ; r-0.760 ; n 24, \\
(\text { SE 0.33) (SE 0.19) }
\end{gathered}
$$

where $r$ is the coefficient of correlation.

Differences in HP before and after fistula-feeding were not significant $(P>0.05)$ (Table 3). As increases in HP after fistula-feeding over the restricted experimental period were negligible, no correction was made to the energy cost of eating for digestion or metabolism of the feed consumed. The nature and physical form of the diet had a marked influence on the energy cost of eating (Table 2). This cost (J/kg BW per $\mathrm{g} \mathrm{DM}$ ) was low for barley grain (1.45), field-bean grain (1.65) and pelleted lucerne hay (2.24) and high for fresh-cut lucerne (7.08) and vetch straw (8.20). Chopped lucerne hay showed an intermediate value (4.75), and the highest corresponded to olive leaves and twigs (11.78). This cost was much lower for concentrates than for forages. Moreover, the cost of eating lucerne was $47 \%$ higher when consumed as chopped hay than as pelleted hay. When the energy cost of eating was expressed per unit of time spent eating (Table 2), it ranged from 45 to $144 \mathrm{~J} / \mathrm{kg} \mathrm{BW}$ per min, according to the physical structure of the feed. The cost was high for barley grain and pelleted lucerne hay $(143.8$ and $135.9 \mathrm{~J} / \mathrm{kg} \mathrm{BW}$ per $\mathrm{min}$ ) and low for fresh-cut lucerne, vetch straw, chopped lucerne hay and field-bean grain $(44.6,63.9$,

Table 3. Heat production $(H P)$ in goats before $\left(H P_{b}\right)$ and after $\left(H P_{a}\right)$ being given barley grain and pelleted lucerne (Medicago sativa) hay by rumen fistula over restricted periods of 15 min

(Mean values for four goats; degrees of freedom of error $=3$ )

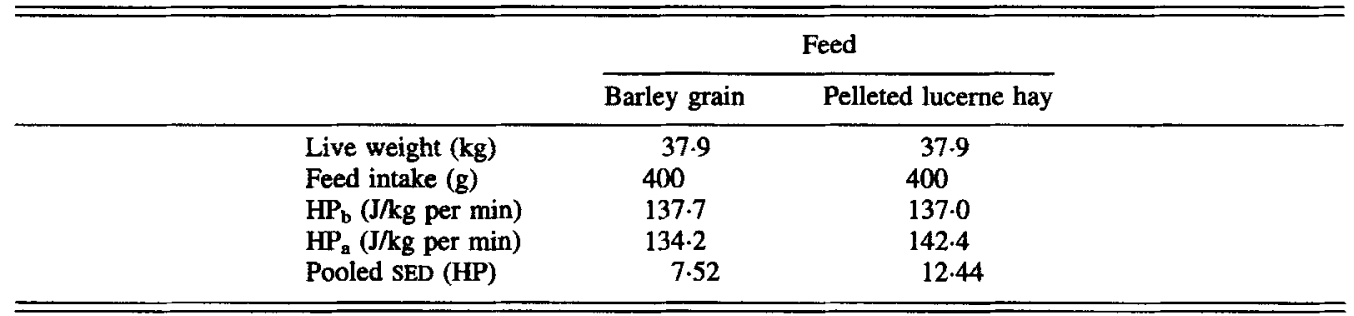


69.8 and $75.8 \mathrm{~J} / \mathrm{kg} \mathrm{BW}$ per min). Olive leaves and twigs showed an intermediate value (97.8 J/kg BW per min).

An inverse exponential relationship was found between the energy cost of eating (CE, $\mathrm{J} / \mathrm{g} \mathrm{DM}$ ) and $\mathrm{R}(\mathrm{g} \mathrm{DM} / \mathrm{min})$ :

$$
\begin{aligned}
& \operatorname{lnCE}=6.78-0.40 \ln R, r 0.97 ; n 24 . \\
& \quad(\text { SE 0.38) (SE 0.18) }
\end{aligned}
$$

When $\mathrm{CE}(\mathrm{J} / \mathrm{g} \mathrm{DM})$ was related to $\mathrm{ADF}$ and $\mathrm{ADL}$, the best fit corresponded to the following exponential equations:

$$
\begin{aligned}
& \operatorname{lnCE}=3.40+0.054 \mathrm{ADF} ; r 0.749 ; n 24, \\
& \quad(\mathrm{SE} 0.32)(\mathrm{SE} \mathrm{0.011)} \\
& \operatorname{lnCE}=3.63+0.201 \mathrm{ADL} ; r 0.883 ; n 24, \\
& \quad(\mathrm{SE} \mathrm{0.17)}(\mathrm{SE} 0.023)
\end{aligned}
$$

where $\mathrm{ADF}$ and $\mathrm{ADL}$ are expressed as $\mathrm{g} / 100 \mathrm{~g} \mathrm{DM}$.

\section{DISCUSSION}

In the present experiments the use of the confinement-type respiration chamber allowed us to obtain accurate gaseous exchange measurements of the fast metabolic response of the animals. In contrast, in some of the previous work (e.g. Osuji, 1971; Osuji et al. 1975) the real energy cost of eating might have been underestimated on the basis of a lag in response due to the size of the open-circuit chamber used. This would generally tend to underestimate HP during such very short-term studies.

Differences in HP before and after fistula-feeding were not significant (Table 3), which indicated that all of the increase in HP over the $15 \mathrm{~min}$ period of eating was to be attributed not to the heat arising from microbial fermentation or work of digestion or nutrient metabolism, but to the energy cost of eating per se, mainly to the cost of biting, chewing, salivating and swallowing throughout the period of feeding. This finding is in agreement with earlier work by Young (1966), using oesophageally fistulated sheep, and by Osuji $e t$ al. (1975), which compared, in sheep, short-term energy exchanges during oral feeding with those during intraruminal feeding.

In all goats and for all the feeds studied there was an increase in HP associated with eating. This increase was related to the nature and physical structure of the feed consumed, in agreement with earlier studies (Blaxter \& Joyce, 1963; Young, 1966; Osuji, 1973). These levels of increase in HP are generally smaller than those published for sheep (50 $60 \%$; Ustjanzew, 1911; Blaxter \& Joyce, 1963). These discrepancies between experiments are explained mainly by differences in the amount of feed eaten.

The DM of pelleted diets and concentrates was eaten considerably faster than that of chopped diets and roughages. Moreover, lucerne hay was eaten faster in pelleted than in chopped form. A similar pattern was obtained previously (Table 4) for cattle (Adam et al. 1984) and sheep (Osuji et al. 1975). The rate of ingestion is influenced by several factors, such as animal species, appetite, bite size and type of feed (Adam et al. 1984). Also it varies considerably between rations and during the meal. In sheep given different types of feed, Graham (1964) found that the rate of ingestion increased when animals ate small meals after long periods without feed, and Young (1966) reported that concentrates were eaten more rapidly during the early part of the meal, but later the rate fell markedly. In constrast, the chaff rations, which were ingested at slower rates, were always consumed at 
Table 4. Comparison of estimates of rates of ingestion and energy cost of eating in ruminants (Mean values with ranges in parentheses)

\begin{tabular}{|c|c|c|c|c|c|}
\hline \multirow[b]{2}{*}{ Species } & \multirow[b]{2}{*}{ Feed or diet } & \multirow{2}{*}{$\begin{array}{l}\text { Rate of ingestion } \\
\quad(\mathrm{g} \mathrm{DM} / \mathrm{min})\end{array}$} & \multicolumn{3}{|c|}{ Energy cost of eating } \\
\hline & & & $\mathrm{J} / \mathrm{kg} \mathrm{BW}$ per g DM & J/kg BW per min & $\% \mathrm{ME}$ \\
\hline \multicolumn{6}{|c|}{ Cattle (mean LW: $353 \mathrm{~kg}$ )* } \\
\hline & Fresh cut forage & $20-25$ & $1.95(1.36-2.44)$ & $40.2(36 \cdot 3-44 \cdot 0)$ & 5.9 \\
\hline & Long, dried forage & $17-37$ & $1.48(1.04-2.21)$ & $32.5(27 \cdot 8-45 \cdot 3)$ & 4.9 \\
\hline & Chopped, dried forage & 39 & 0.79 & $27 \cdot 6$ & $2 \cdot 5$ \\
\hline & Pelleted food and grain & $130-138$ & $0.23(0.22-0.24)$ & $23.8(19.4-28.9)$ & 1.0 \\
\hline \multicolumn{6}{|c|}{ Sheep (mean LW: $52 \mathrm{~kg}) \dagger$} \\
\hline & Fresh cut forage & $4-7$ & $5.12(3.09-6.20)$ & $36 \cdot 2(29 \cdot 3-46 \cdot 4)$ & 2.6 \\
\hline & Long, dried forage & $8-9$ & 6.95 & $54 \cdot 9(45 \cdot 8-61 \cdot 5)$ & $3 \cdot 9$ \\
\hline & Chopped, dried forage & $4-14$ & $4.01(1.91-7.95)$ & $38.1(33.8-43.1)$ & 2.5 \\
\hline & Pelleted food and grain & $8-58$ & $1.07(0.30-2.51)$ & $36.6(18.4-63.4)$ & 0.4 \\
\hline \multicolumn{6}{|c|}{ Goat (mean LW: $35 \mathrm{~kg}$ ) $\ddagger$} \\
\hline & Fresh cut forage & 7 & 7.03 & $44 \cdot 3$ & $3 \cdot 2$ \\
\hline & Long, dried forage & 8 & 12.04 & $97 \cdot 1$ & $4 \cdot 7$ \\
\hline & Chopped, dried forage & $8-15$ & $6.50(4.77-8.23)$ & $66.7(63.8-69.5)$ & $3 \cdot 1$ \\
\hline & Pelleted food and grain & $46-99$ & $1.80(1.44-2.28)$ & $118 \cdot 3(75 \cdot 7-143 \cdot 6)$ & 0.7 \\
\hline
\end{tabular}

BW, body weight; ME, metabolizable energy; LW, live weight.

*Adam et al. (1984).

†Osuji et al. (1975).

\$Present study.

approximately the same rate. The rate of ingestion was negatively related to the fibre level. The higher rate of eating was related to the lower ADF and ADL levels and vice versa. A similar relationship has been reported previously for both sheep (Forbes et al. 1972) and cattle (Frisch \& Vercoe, 1977; McLeod \& Smith, 1989). This fact could be due to a higher difficulty in either prehending, forming a bolus or chewing when the animal has access to food containing more fibrous fractions (Dulphy et al. 1980). With respect to this point, one of the factors controlling the voluntary intake by ruminants is the rate at which large food particles are reduced to a size small enough to leave the rumen (Freer et al. 1962). Eating and rumination are the main contributors to this process and both are affected by the fibre level of the diet (Harumoto \& Kato, 1978; Fujihara \& Nakao, 1982).

The estimates of energy cost in $\mathrm{J} / \mathrm{min}$, as a function of both the rate of ingestion ( $\mathrm{g}$ $\mathrm{DM} / \mathrm{min}$ ) and the energy cost of eating expressed as $\mathrm{J} / \mathrm{g} \mathrm{DM}$, are in goats, higher (Table 4) than those published for cattle (Adam et al. 1984) and sheep (Osuji et al. 1975). However, when comparisons are established in terms of J/g DM ingested or as $\mathrm{kJ} / 100 \mathrm{~kJ}$ ME ingested (Table 4), energy cost values between species are similar, a fact which raises uncertainty about the more adequate way of expressing these costs for comparative purposes. In respect of this matter, it is questionable to express the energy cost per unit time (J/min) on the basis of the variability associated with the rate of ingestion.

There was a significant negative relationship between $\mathrm{CE}(\mathrm{J} / \mathrm{g} \mathrm{DM})$ and $\mathrm{R}$ (g DM/min; equation 3). The higher $\mathrm{CE}$ was related to the lower $\mathrm{R}$ and vice versa. This is in agreement with results by Osuji (1971) with sheep given different types of diet. He also found that it was more energetically expensive to consume a particular diet at a more rapid rate. Moreover, the CE (J/g DM) was also related to the content of ADF and ADL (g/100 g DM; equations 4 and 5). This fact can partly explain the high energetic cost found for olive leaves and twigs and for vetch straw (Table 2).

The ME contents of the feeds tested were estimated from their chemical composition 
and DOM (Table 1). The CE (Table 4) ranged from $0.7 \% \mathrm{ME}$ for grains and pelleted lucerne hay to $3.1 \%$ ME for chopped dried forages (chopped lucerne hay and vetch straw) and up to $4.7 \% \mathrm{ME}$ for olive leaves and twigs. The value obtained for fresh-cut lucerne (3.2\% ME) may have been due to its high water content. Our results suggest that the act of eating accounts for an energy cost of about 1-5\% of the ME ingested (Tables 2 and 4), varying with the type of food consumed. These values are in agreement with previous results published (Table 4) for cattle (Adam et al. 1984) and sheep (Osuji et al. 1975).

Some of the factors which may contribute to CE have been discussed by Osuji (1974) and Webster $(1972,1978)$. This cost per se is minor in comparison with the total heat increment of feeding, which also results from the energy cost of rumination, the heat of fermentation, the work of digestion and the work of nutrient metabolism. The Agricultural Research Council (1980) stated that the energy cost of eating may be neglected for practical purposes. This conclusion may be applicable to ruminants eating prepared and accessible food, the energy cost of which is probably less than $3 \%$ of its ME (see Table 4), but seems unlikely for grazing animals. In such conditions the $\mathrm{CE}$ can make an important contribution to the energy requirement of the animals. Osuji (1974), using an indirect theoretical approach to predicting the energy expenditure of a $50 \mathrm{~kg}$ sheep on range, estimated that the contribution of eating would account for an increase in HP of $17 \%$ above that of a confined animal. Webster (1978), by means of the same approach, calculated that for a $500 \mathrm{~kg}$ steer the additional energy cost of eating on range would represent an increase in HP of 5-9.3\% compared with that of a similar animal kept indoors. Prieto et al. (1992) estimated, in a semi-arid zone located in southern Spain, the free-ranging energy expenditure of Granadina goats. A factorial method was used, based on both the results of the CE of the present work and the direct observation of the time spent by the animals eating different biotypes. The mean increase in energy expenditure above maintenance due to the act of feeding was estimated to range from $6.6 \%$ in summer to $11.1 \%$ in spring, with a mean annual value of $8.8 \%$. Due to the great difficulties encountered when evaluating the main factors associated with eating in field studies (quantity and quality of the feed consumed, time spent eating, pattern of feed consumption, etc.), the extrapolation of data obtained in confined animals to grazing animals for estimation of the energy expenditure due to the act of eating may be misleading. Further investigation is urgently needed to make the required measurements to develop and improve new techniques in grazing systems.

In conclusion, these trials suggest that:

(1) eating in goats was associated with an increase in HP. This increase was due to the cost of eating per se (food prehension, mastication and propulsion into the alimentary tract);

(2) the energy cost of eating was influenced by the nature and physical form of the diet and was proportional to the length of time spent eating;

(3) in grazing conditions, this cost can make a significant contribution to the maintenance energy requirement of the goats.

The authors wish to thank Dr J. C. MacRae for helpful discussion and for critically reading the manuscript. This work was supported by LUCDEME Program (CSIC-ICONA).

\section{REFERENCES}

Adam, I., Young, B. A., Nicol, A. M. \& Degen, A. A. (1984). Energy cost of eating in cattle given diets of different form. Animal Production 38, 53-56.

Agricultural Research Council (1980). The Nutrient Requirements of Ruminants Livestock. Slough: Commonwealth Agricultural Bureaux. 
Aguilera, J. F., Prieto, C. \& Fonolla, J. (1990). Protein and energy metabolism of lactating Granadina goats. British Joumal of Nutrition 63, 165-175.

Blaxter, K. (1989) Energy metabolism in Animals and Man. Cambridge: Cambridge University Press.

Blaxter, K. L. \& Joyce, J. P. (1963). The accuracy and ease with which measurements of respiratory metabolism can be made with tracheostomized sheep. British Journal of Nutrition 17, 523-537.

Brouwer, E. (1965). Report of subcommittee on constants and factors. In Energy Metabolism. EAAP Publication no 11, pp. $441-443$ [K.L. Blaxter, editor]. London: Academic Press.

Dulphy, J. P., Remond, B. \& Theriez, M. (1980). Ingestive behaviour and related activities in ruminants. In Digestive Physiology and Metabolism in Ruminants, pp. 103-122. [Y. Ruckebusch and P. Thivend, editors]. Connecticut: AVI Publishing Company.

Forbes, J. M., Wright, J. A. \& Bannister, A. (1972). A note on rate of eating in sheep. Animal Production 15, 211-214.

Freer, M., Campling, R. C. \& Balch, C. C. (1962). Factors affecting the voluntary intake of food by cows. 4. The behaviour and reticular motility of cows receiving diets of hay, oat straw and oat straw with urea. British Journal of Nutrition 16, 279-295.

Frisch, J. E. \& Vercoe, K. E. (1977). Food intake, eating rate, weight gains, metabolic rate and efficiency of feed utilization in Bos taurus and Bos indicus crossbred cattle. Animal Production 25, 343-358.

Fujihara, T. \& Nakao, T. (1982). Eating and rumination behaviour in sheep given silage made from the fibrous residue of broad bean (Vicia faba L.). Journal of Agricultural Science, Cambridge 98, 237-240.

Graham, N. Mc. (1964). Energy cost of feeding activities and energy expenditure of grazing sheep. Australian Journal of Agricultural Research 15, 969-973.

Harumoto, T. \& Kato, M. (1978). Effect of crude fibre content in the diets on ruminating behaviour of sheep. Bulletin of the Faculty of Agriculture, Shimane University 12, 26-30.

Lachica, M., Aguilera, J. F. \& Prieto, C. (1994). Energy expenditure associated with feeding in Granadina goats. In Energy Metabolism of Farm Animals. EAAP Publication no. 76, pp. 347-350 [J. F. Aguilera, editor]. Madrid: CSIC.

McLeod, M. N. \& Smith, B. R. (1989). Eating and ruminating behaviour in cattle given forages differing in fibre content. Animal Production 48, 503-511.

Osuji, P. O. (1971). Energy exchanges and related phenomena in sheep eating rations of different physical form. MSc Thesis, University of Aberdeen.

Osuji, P. O. (1973). Ruminant energy metabolism: an analysis of the heat increment of feeding in sheep. $\mathrm{PhD}$ Thesis, University of Aberdeen.

Osuji, P. O. (1974). The physiology of eating and the energy expenditure of the ruminant at pasture. Journal of Range Management 27, 437-443.

Osuji, P. O., Gordon, J. G. \& Webster, A. J. F. (1975). Energy exchanges associated with eating and rumination of sheep given grass diets of different physical form. British Journal of Nutrition 34, 59-71.

Prieto, C., Lachica, M., García Barroso, F. \& Aguilera, J. F. (1992). Energy expenditure by grazing animals. Proceedings of the 43rd Annual Meeting of the EAAP, vol. 2, p. 171. Madrid: Spanish Ministry of Agriculture, Fishing and Food.

Ustjanzew, W. (1911). Die energetische Aquvalente det Verdaungsatbeit bei den Wiederkaurn (Schage) (The energy cost of ingestion by sheep). Biochemische Zeitschrift 37, 475.

Vermorel, M. \& Mormede, P. (1991). Energy cost of eating in ponies. In Energy Metabolism of Farm Animals. EAAP Publication no. 58, pp. 437-440 [C. Wenk and M. Boessinger, editors]. Zurich: Institut für Nutztierwissenschaften.

Webster, A. J. F. (1972). Act of eating and its relation to the heat increment of feed in ruminants. In Bioenergetics International Symposium on Environment Physiology, Dublin, pp. 42-48. Dublin: American Society of Experimental Biology.

Webster, A. J. F. (1978). Prediction of the energy requirements for growth in beef cattle. World Review of Nutrition and Dietetics 30, 189-226.

Webster, A. J. F. \& Hays, F. L. (1968). Effects of beta-adrenergic blockade on the heart rate and energy expenditure of sheep during feeding and during acute cold exposure. Canadian Journal of Physiology and Pharmacology 46, 577-583.

Young, B. A. (1966). Energy expenditure and respiratory activity of sheep during feeding. Australian Journal of Agricultural Research 17, 335-362. 